\title{
Is There a Crisis in Heart Transplantation? Reflection over 10 Years
}

\author{
Karin Purshouse ${ }^{1}$, Stephen Large ${ }^{2 *}$, Henry Dargie ${ }^{3}$, John Dunning ${ }^{2}$, James Neuberger ${ }^{4}$ \\ ${ }^{1}$ Newcastle University, Newcastle, UK \\ ${ }^{2}$ Papworth Hospital, Cambridge, UK \\ ${ }^{3}$ Hon Consultant Cardiologist Western Infirmary, Glasgow, UK \\ ${ }^{4}$ Associate Medical Director for NHS Blood and Transplant, Queen Elizabeth Hospital, Birmingham, UK \\ Email: *s.large@nhs.net
}

Received October 14, 2011; revised December 1, 2011; accepted December 20, 2011

\begin{abstract}
Heart transplantation is without doubt a very effective treatment for patients' whose lives and well- being are threatened by their failing heart. We previously categorized our concerns into four areas or Ds: Donor availability, Disorganization, Disillusionment (of clinicians) and Disaffection (of tomorrow's clinicians). After a decade, this is a timely reflection on this crisis of cardiac transplantation. It is also appropriate to set this in the context of a fifth D, the Demand for heart transplantation. In this reflective analysis, we use the 5 Ds to explore the current climate in heart transplantation, with particular reference to the situation in the UK.
\end{abstract}

Keywords: Heart Transplantation; Heart Failure

\section{The 5 Ds}

It is almost a decade since we asked the question "Is there a crisis in cardiac transplantation" [1]. Heart transplantation is without doubt a very effective treatment for patients with heart failure, and a decade has passed since we explored a potential crisis in cardiac transplantation. We categorized our concerns into four areas or Ds: Donor availability, Disorganization, Disillusionment (of clinicians) and Disaffection (of tomorrow's clinicians) [1]. So how have things changed in the last 10 years in the UK? MacGowan and colleagues recently discussed the decline in cardiac transplantation, focusing on the evolution of surgical techniques [2]. Here, we add a fifth D-Demand and present a detailed exploration of the "Five Ds" to build on the findings of previous commentaries.

There are good data available now, so much so that we can see clearly a steady decline in the number of cardiothoracic donor organs available and transplants undertaken. UK cardio-thoracic donor organ numbers have halved from 244 to 115 between 1999 and 2010, with the number of transplants falling correspondingly in this period [3]. In 2002 we described a "life cycle of cardiac transplantation" similar to that seen in industry [1], with growth, mature and decline phases and demonstrated that it was in decline 10 years ago. Data from the International Society for Heart and Lung Transplantation (ISHLT) indicates continued decline [4].

This is not restricted to the UK as the number of trans- plants has been declining steadily worldwide (Figure 1).

\subsection{Disorganisation}

Whilst it would be easy to simply blame the decline in transplantation on the fall in donors, we have sought to explore the wider barriers and consequences thereof on cardiac transplantation. It is our opinion that there are various levels at which disorganisation might limit a donor organ being used, and it is clear that some of these have improved [1]. Barriers to transplantation may be neatly categorised into three groups which will be evaluated in turn: 1) donor registration, 2) converting a potential donor organ into an available organ, and 3) the even-

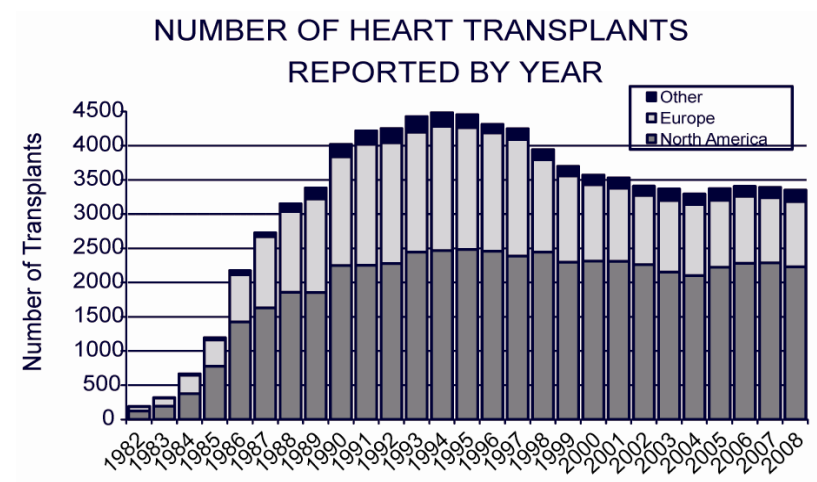

Figure 1. Number of Heart Transplants reported by year. With kind permission from ISHLT (2010). 
tual use of the organ.

1) In terms of organ registration: NHS Blood and Transplant has done much to improve donor registration organisation, and subsequently just over a quarter of the UK population are on the organ donor list. The issue of low donor supply has been tackled by developing innovative donor registration routes, such as through the Driver and Vehicle Licensing Agency (DVLA), when registering with a General Practitioner or when applying for a store card with a national chemist chain. Recently they launched the first multi-media campaign. Despite these efforts, registration rates remain low. In addition, only $38 \%$ of heart-beating solid organ donors permit the donation of cardiothoracic organs [3]. Perhaps there is a Distaste for heart transplantation in our population which is proving the limiting factor, and a fear of planning for the end of life at a young age [5].

2) The undertaking of the recent National Potential Donor Audit (a 24 month study between April 2007 and March 2009) showed 30,693 deaths in UK intensive care units (ICUs) (15,342 per year) and the process of translation into solid organ donation. Brain stem death was present in some $10 \%$ (3065). Organ donation was principally lost through failure to perform brain-stem death tests in $23 \%$ of this group and further $37 \%$ where consent for organ donation was not obtained [6]. Two hundred and fifty eight heart transplants were performed in this 24 month period representing $8 \%$ of all ITU deaths [3]. Ongoing priorities include engagement with ICU teams to encourage donation and clarify ethical and legal matters, and removal of the financial barriers that exist in UK hospitals for the high cost of retrieving organs by reimbursing hospitals.

3) $97 \%$ of hearts retrieved were subsequently transplanted [3].

\subsection{Donor Availability}

Donor availability is part of the problem despite an increase in the number of donor registrations (over 16 million out of a UK population of around 60 million) [3]. More worrisome is donor usage. Although organ donation continues to fall, $33 \%$ of the 623 solid organ donors donated cardiothoracic organs but only 19\% (120) of hearts were transplanted: a rate of 1 used for every 5 donated, with no clear medical justification for not using the remainder [3]. Ten years ago this was of the order of 1 used of every 3 offered. The reality remains that in the UK only $43 \%$ of those waiting on transplant lists are transplanted, with $9 \%$ dying whilst awaiting a heart [3] and so many more removed from the list due to deterioration of their condition making them no longer candidates for heart transplantation. The number of patients on the waiting list for heart transplantation has probably never reflected demand and especially so lately with more than $50 \%$ of hearts transplants in the UK now being labelled as "urgent"; that is, an acutely ill patient deteriorating too fast to get on to the waiting list. These patients form the tip of a huge iceberg that is made up of the cardiac deaths in younger people following myocardial infarction at a rate of some 600/100,000. A recent survey in Scotland has shown that in 2009/10 there were 415 deaths in patients under 65 years of age who died either in hospital or in the 1st year after admission for either acute MI or heart failure (personal communication: Professor Henry Dargie, Hon Consultant Cardiologist Western Infirmary Glasgow, Former Director of Scottish Advanced Heart Failure Service).

\subsection{Disillusionment}

We previously identified a three-and-a-half fold difference between individual surgeon's operating activities (i.e. number of operations) within units. Things have changed: units are fewer (6 adult for the UK) and clinical activity more evenly shared amongst colleagues. However there is a national performance measure to be met, demanding a reasonable transplant unit survival for heart recipients at 12 months. It may be an unrealistic bar to scale considering the direction of clinical heart transplant activity which is aimed at a population whose life expectancy is likely to be $50 \%$ at one year and, overall, no more than 2 years. A number of units have failed to achieve this outcome at times leading to reviews of practice. It may be that such a demand is leading to disillusionment amongst transplantation surgeons.

\subsection{Disaffection}

It is important to highlight that activity, described as 115 operations in 2009, amalgamates pediatric and adult heart transplantation. There are three pediatric centres and six adult for the UK (two combined units and one stand alone pediatric centre: a total of seven overall). Each unit can hope for an annual activity of 22 heart transplants but reality shows that two centres had an annual activity below 10. Each unit will each have five surgeons or so which translates into an individual annual experience of three heart transplants. Is this enough to maintain the competency of a surgeon? Certainly heart transplantation is seen as a demanding career by tomorrow's clinicians and our concerns that transplant Units' reliance on senior surgeons indicates a continuing Disaffection towards heart transplantation amongst trainees.

\subsection{Demand}

So what of the Demand for cardiac transplantation? There has been a $48 \%$ decrease in the number of patients Registered on the active heart transplant list between 2000 and 2009 [3]. This does not necessarily suggest that Demand 
is waning. This waiting list reduction could be due to the waiting list protocol introduced in 2002. The reality is that at least half of the patients undergoing transplantation deteriorate too quickly to get on to a waiting list, undergoing urgent heart transplantation. Waiting lists aside, what is the Demand likely to be if all patients had ready access to heart transplantation? If we use the number of deaths from acute myocardial infarction in those aged less than 70 years as a crude measure of potentially salvageable lives we find that over 6500 lives could be saved based on deaths registered in 2008 [7]. This loosely defined group represents $22.6 \%$ of all deaths from acute myocardial infarction, indicating a massive Demand. The National Heart Failure Audit further notes $47.5 \%$ of all patients admitted with acute heart failure have either died or been readmitted at one year [8]. We are not alone in highlighting the significant demand. It is sobering to recall that the National Service Framework 2000 set a standard for patients in heart failure, stating that "treatments most likely to both relieve their symptoms and reduce their risk of death should be offered" [9].

\section{A Future for Heart Transplantation?}

What does the future hold for heart transplantation? It's tempting to say "not much" unless we address the following 5 points:

1) The possibility of obtaining hearts from new sources. Animals as heart donors (xenografts) continue to be explored and optimism remains high that research will translate into clinical trials [10]. Non heart-beating or Donation after Cardiac Death (DCD) heart donation remains at an experimental stage but shows promise. Ali et al. have identified that DCD donation may be appropriate for cardiac transplantation and requires continued investigation [11]. Renal DCD grafts seem to be as successful as grafts from brain dead donors (DBD) [12]. These measures may lead to an increase in donor hearts.

2) Review the expectation of high survival at one year after heart transplantation. Hypothetically, sixty adult heart transplants (the number of operations this year) with, say, 90\% survival promises 54 patients will survive to one year. However 250 patients receiving heart transplants with a lower $(70 \%)$ expected survival at one year gives 187 the chance of surviving beyond one year. This apparent relaxing of standards appears to be unattractive by significantly raising the patient's risk of death following heart transplantation as seen at 1 year. Of course, it does mean that more patients hoping for heart transplantation will receive this life saving treatment.

3) In terms of volume of providers it would be wise to reduce the number of centres offering heart transplantation if only to ensure individual centres and their clini- cians' competence as activity continues to fall.

4) Used as a bridge to transplantation, mechanical support in the form of implantable heart assist devices allows patients to live independently with improved quality of life whilst waiting for a transplant. They are also recommended as destination therapy in heart failure and used as such in $10 \%$ of patients, despite inferior long term outcomes compared with transplantation $[13,14]$.

5) In the future, biological repowering of the failing heart, perhaps with progenitor cell technology, may buy time for patients waiting for a transplant [15].

Without these steps the crisis of heart transplantation will be resolved by Disappearance of this extraordinarily effective therapy.

\section{REFERENCES}

[1] S. Large, "Is There a Crisis in Cardiac Transplantation," The Lancet, Vol. 359, No. 9308, 2002, pp. 803-804. doi:10.1016/S0140-6736(02)07870-4

[2] G. A. Macgowan, G. Parry, S. Schueler and A. Hasan, "The Decline in Heart Transplantation in the UK," British Medical Journal, Vol. 342, 2011, p. d2483.

[3] "NHS Blood and Transplant Annual Report 2009/10. Transplant activity in the UK," 2011.

http://www.organdonation.nhs.uk/ukt/statistics/transplant _activity_report/current_activity_reports/ukt/activity_rep ort_2009_10.pdf

[4] C. Murphy and C. Counter, "National Potential Donor Audit Summary Report for the Period 1st April 2007 31st March 2009,” NHS Blood and Transplant, 2009.

[5] C. Conesa, A. R. Zambudio, P. Ramírez, M. Canteras, M. del Rodríguez and P. Parrilla, "Socio-Personal Profile of Teenagers Opposed to Organ Donation,” Nephrology Dialysis Transplantation, Vol. 19, No. 5, 2004, pp. 12691275. doi:10.1093/ndt/gfh075

[6] J. Stehlik, L. B. Edwards, A. Y. Kucheryavaya, P. Aurora, J. D. Christie, R. Kirk, F. Dobbels, A. O. Rahmel and M. I. Hertz, "The Registry of the International Society for Heart and Lung Transplantation: Twenty-Seventh Official Adult Heart Transplant Report-2010," The Journal of Heart and Lung Transplantation, Vol. 29, No. 10, 2010, pp. 1089-1103. doi:10.1016/j.healun.2010.08.007

[7] Office of National Statistics, Deaths Registered in 2008, August 2009.

[8] National Heart Failure Audit 2008/2009, NHS Information Centre, 2009.

[9] NHS-Our Healthier Nation, National Service Framework-Coronary Heart Disease. 2000.

[10] R. N. Pierson III, A. Dorling, D. Ayares, M. A. Rees, J. D. Seebach, J. A. Fishman, B. J. Hering and D. K. Cooper, "Current Status of Xenotransplantation and Prospects for Clinical Application,” Xenotransplantation, Vol. 16, No. 5, 2009, pp. 263-280. doi:10.1111/j.1399-3089.2009.00534.x

[11] A. Ali, P. White, K. Dhital, M. Ryan, S. Tsui and S. 
Large, "Cardiac Recovery in a Human Non-Heart-Beating Donor after Extracorporeal Perfusion: Source for Human Heart Donation?” Journal of Heart \& Lung Transplantation, Vol. 29, No. 3, 2009, pp. 290-293.

[12] A. D. Barlow, M. S. Metcalfe, Y. Johari, R. Elwell, P. S. Veitch and M. L. Nicholson, "Case-Matched Comparison of Long-Term Results of Non-Heart Beating and HeartBeating Donor Renal Transplants," British Journal of Surgery, Vol. 96, No. 6, 2009, pp. 685-691. doi:10.1002/bjs.6607

[13] J. K. Kirklin, D. C. Naftel, R. L. Kormos, L. W. Stevenson, F. D. Pagani, M. A. Miller, K. L. Ulisney, J. T. Baldwin and J. B. Young, "Second INTERMACS Annual Report: More Than 1,000 Primary Left Ventricular Assist Device Implants," The Journal of Heart and Lung Transplantation, Vol. 29, No. 1, 2010, pp. 1-10. doi:10.1016/j.healun.2009.10.009

[14] K. Dickstein, P. E. Vardas, A. Auricchio, J. C. Daubert, C. Linde, J. McMurray, P. Ponikowski, S. G. Priori, R. Sut- ton and D. J. van Veldhuisen, ESC Committee for Practice Guidelines (CPG), A. Vahanian, A. Auricchio, J. Bax, C. Ceconi, V. Dean, G. Filippatos, C. Funck-Brentano, R. Hobbs, P. Kearney, T. McDonagh, B. A. Popescu, Z. Reiner, U. Sechtem, P. A. Sirnes, M. Tendera, P. Vardas, P. Widimsky, Document Reviewers, M. Tendera, S. D. Anker, J. J. Blanc, M. Gasparini, A. W. Hoes, C. W. Israel, Z. Kalarus, B. Merkely, K. Swedberg, A. J. Camm, "2010 Focused Update of ESC Guidelines on Device Therapy in Heart Failure: An Update of the 2008 ESC Guidelines for the Diagnosis and Treatment of Acute and Chronic Heart Failure and the 2007 ESC Guidelines for Cardiac and Resynchronization Therapy. Developed with the Special Contribution of the Heart Failure Association and the European Heart Rhythm Association,” European Heart Journal, Vol. 31, No. 21, 2010, pp. 2677-2687.

[15] V. Schächinger, Intracoronary Bone Marrow-Derived Progenitor Cells in Acute Myocardial Infarction,” The New England Journal of Medicine, Vol. 355, No. 12, 2006, pp. 1210-1221. doi:10.1056/NEJMoa060186 